Almeida, Carla Aurélia de (2015) "Estratégias discursivas de mitigação na sequência discursiva de pergunta-resposta: a justificação no contexto de entrevista”. In Moreno, António; Silva, Fátima; Veloso, João (orgs.) Textos Selecionados, XXX Encontro Nacional da Associação Portuguesa de Linguística no Porto, Porto, APL, pp. 65-76, ISBN 978-989-97440-4-2. (outubro de 2015)

\title{
Estratégias discursivas de mitigação na sequência discursiva de pergunta- resposta: a justificação no contexto de entrevista
}

\author{
Carla Aurélia de Almeida \\ Departamento de Humanidades da Universidade Aberta \\ Instituto de Sociologia da Universidade do Porto
}

Versão pré-publicada

\begin{abstract}
Taking as reference an oral corpus of narratives of life experience collected in interviews, we will analyse the question-answer sequence and the justification sequence. As a pre-sequence that prepares the act of question, anticipating possible objections from the interviewee, justification constitutes an argumentative strategy, developed by the interviewer, at the service of interactional achievement. We will also study the interviewees' answers followed by justification, specifically those at the service of the mitigation of epistemic values, representing a strategy of mitigation and softening what is being said in the propositional content of the answer, reducing the epistemic obligations of the interviewee.
\end{abstract}

Keywords: illocutionary act; sequences of justification; mitigation; interviews; discourse strategies Palavras-chave: ato ilocutório; sequências de justificação; mitigação; entrevistas; estratégias discursivas

\section{Introdução}

Tendo por base um corpus oral constituído por narrativas de experiencia de vida realizadas em contexto de entrevista (Almeida, 2012), procederemos ao levantamento dos padrões de organização sequencial dos atos ilocutórios realizados na situação de entrevista de investigação (Myers; Lampropoulou 2012), especificamente, a sequência discursiva de pergunta-resposta e o contexto em que se realiza a sequência discursiva de justificação, ato ilocutório de "natureza sequencial" (Fonseca, 1992: 299), que permite o estabelecimento de coerências semântico-pragmáticas específicas (Lopes, 2009).

O enfoque teórico e metodológico deste trabalho é orientado por uma perspetiva semântico-pragmática da organização e do funcionamento do discurso interativo oral processado em situação de entrevista, tendo por referencial teórico e metodológico o conjunto de perspetivas que se inscrevem na Análise Interacional (KerbratOrecchioni, 2010: 71-97).

A nível global ou macroestrutural, estudaremos a coerência pragmático-funcional do discurso que diz respeito fundamentalmente às dimensões sequenciais dos atos ilocutórios (Fonseca, 1992: 269), analisando o funcionamento da sequência de justificação que, prototipicamente, coocorre com a sequência de perguntaresposta, considerando a figuração (Goffman, 1981) que os interactantes desenvolvem face a face.

A nível local, analisaremos as ações do entrevistador que dizem respeito à realização de asserções avaliativas após o ato de resposta e ao estudo de sequências de justificação que precedem o ato de pergunta: sendo uma pré-sequência (Schegloff, 1988) que prepara o ato de pergunta, antecipando as possíveis objeções do entrevistado, a justificação, nestes contextos interacionais e interlocutivos, constitui, regularmente, uma estratégia, dinamizada pelo entrevistador, para evitar os valores mais ameaçadores da face, uma ação estratégica ao serviço da eficácia interacional (Fraser, 1980: 341; Fraser, 2010: 31) e, por conseguinte, um atenuador ou amenizador ("suavizador ritual”, Kerbrat-Orecchioni, 2005). 
Por fim, estudaremos as respostas do entrevistado seguidas de justificação, especificamente, as que estão ao serviço da mitigação dos valores epistémicos, constituindo uma estratégia de mitigação e/ou atenuação do que é dito no conteúdo proposicional da resposta, reduzindo as obrigações epistémicas (Caffi, 2000: 96) do locutor/entrevistado.

\section{Corpus e metodologia}

O corpus de entrevistas foi recolhido e transcrito em 2009 e 2010 no âmbito de um projeto de investigação constituído por uma equipa multidisciplinar de investigadores que integram o Instituto de Sociologia da Universidade do Porto. O projeto em causa, intitulado "A Formação do Quotidiano Operário: Sociedade, Economia e Cultura num Contexto (Des)Industrializado do Vale do Ave (2009-2012)", permitiu recolher informação empírica que é estudada multidisciplinarmente em Pereira (2012). O corpus é constituído por 23 entrevistas de duas horas e meia cada uma a residentes nas freguesias, pertencentes ao concelho de Vila de Nova de Famalicão, de Riba de Ave e de Oliveira de São Mateus. Os entrevistados foram previamente selecionados depois de responderem a um inquérito por questionário que envolveu 319 grupos domésticos e recenseou informação de 904 indivíduos. Não obstante este enquadramento, a orientação teórica e metodológica de análise do discurso das entrevistas, aqui apresentada, enfatiza questões de índole qualitativa. Com a realização das entrevistas procurou aprofundar-se o conhecimento de questões previamente trabalhadas no inquérito. $\mathrm{O}$ guião das entrevistas foi concebido de acordo com os seguintes temas: caracterização da relação com trabalho; o retrato da escola; a casa e a descrição da vida familiar; as relações sociais no interior do contexto de trabalho; as relações de vizinhança e os processos de identificação com o contexto local; as principais vivências do período de reforma e/ou desemprego; os momentos de emigração e as principais disposições/vivências políticas e religiosas (cf. Almeida, 2012a). Realizaram-se contatos com outras entidades locais com vista à recolha de testemunhos complementares.

Percorre o discurso dos entrevistados a referência constante ao desemprego e às razões desta situação, que envolve, na grande maioria dos casos o encerramento de empresa e o despedimento. O contexto dos entrevistados é constituído por um tecido social onde a taxa de desemprego é, por isso, elevada (em Oliveira de São Mateus é de $25 \%$ e a taxa de desemprego em Riba de Ave é de 23\%). Os entrevistados analisados pertencem ao Operariado Industrial.

No quadro interacional constituído pelos entrevistadores e entrevistados, verificamos que, nestes contextos interativos e interlocutivos, os participantes acionam um sistema de práticas, de convenções sociais e de regras de procedimento discursivo que organizam sequencialmente as interações conversacionais.

A transcrição do corpus teve por base o sistema de notação da transcrição ortográfica utilizado na Linguística do Corpus Oral de Portugal (Bacelar, 1987; Ramilo; Freitas, 2002).

\section{Ações do entrevistador: sequências de justificação como pré-sequências}

Consideraremos as pré-sequências de explicação e de justificação ao serviço da eficiência interacional, isto é, analisaremos as estratégias de alinhamento ("the interactional 'footing"”, Segundo Firth, 1995: 29) realizadas pelo entrevistador.

Observemos o seguinte exemplo:

(1) (E: Entrevistador do sexo feminino; e: Entrevistada; e2: (filha); e3: (irmã)

Data: 23 de novembro de 2010

Local: Riba de Ave (Zona da Sampaio Ferreira)

$\rightarrow$ Entrevistadora: Então em primeiro lugar, eh e de acordo com o que pudemos aferir do inquérito, sei que inicialmente começou a trabalhar jovem eh, na altura, penso que com quinze anos?

Entrevistada: Sim, sim.

Entrevistadora: Trabalhou numa empresa de bordados..

Entrevistada: Sim.

Entrevistadora: Ou ligada a essa área...

Entrevistada: Sim, sim, sim. Foram eh poucos meses e eh era uma empresa pequena. Éramos praí dez, dez, doze empregadas eh nem sequer descontava pra Caixa. [risos]

Entrevistadora: Exato. Hum, hum. 
A sequência iniciativa da entrevistadora prepara o ato de pergunta: esta pré-sequência constitui uma asserção avaliativa que resume o percurso da entrevistada e faz parte de uma estratégia retórica do entrevistador de empregar um discurso com mitigadores e hesitações que revelam a sua precaução para não ameaçar a face do entrevistado: a asserção é precedida pela hesitação "eh" e a proposição ocorre mitigada, apresentando um valor epistémico no domínio da incerteza que, argumentativamente, cria a distância entre o entrevistador e o que está a ser dito: "eh e de acordo com o que pudemos aferir do inquérito". A asserção avaliativa "começou a trabalhar jovem”, seguida da hesitação "eh" e da pergunta de confirmação "na altura, penso que com quinze anos?", demonstra uma ordem ritual de evitar ameaçar não só a face negativa que é inerente ao ato de pergunta, mas também constitui uma estratégia de evitação da ameaça da face positiva da entrevistada que começou a trabalhar muito jovem. Esta precaução ritual de salvar a face permitirá à entrevistada responder, justificando: "Sim, sim, sim. Foram eh poucos meses e eh era uma empresa pequena. Éramos praí dez, dez, doze empregadas eh nem sequer descontava pra Caixa. [risos]". Este ultimo segmento "eh nem sequer descontava pra Caixa. [risos]" permite à entrevistada explicar que era muito jovem para trabalhar e justificar a afirmação apresentada na resposta de que "era uma empresa pequena". Como iremos ver no ponto seguinte, a sequência de justificação, neste contexto de entrevista de investigação que incide sobre o estilo de vida e a relação dos entrevistados com o trabalho, constituindo a terceira sequência do par adjacente pergunta-resposta, está ao serviço da salvaguarda da própria face positiva dos entrevistados.

Neste contexto interacional, os entrevistadores, regularmente, realizam uma sequência de justificação como pré-sequência que prepara o ato de pergunta, funcionando como uma estratégia discursiva ao serviço da eficácia interacional e evitando ameaçar demasiado a face negativa dos entrevistados com perguntas indiscretas. Com as perguntas de confirmação que apresentam conteúdos proposicionais delicados em termos sociais, os entrevistadores procuram evitar os valores mais ameaçadores da face positiva dos entrevistados com a realização de sequências de justificação que preparam as perguntas.

Assim, no corpus de entrevistas analisado, verificamos que o entrevistador realiza pré-sequências de justificação em intervenções diretivas que funcionam como estratégias de alinhamento:

(2) ID: Entrevista RdA 13 MIC;

Tipo: Inquiridos; Entrevistados: C. M.;

Data: 23/11/2010;

Local: Riba de Ave

(Zona de Sampaio Ferreira)

Entrevistador: sexo feminino; e1: C. M.; e2: (filha); e3: (irmã)

Entrevistadora: Claro, claro.

(...)

Entrevistada 1: E digo logo. Quando alguém diz: "Hoje atrasaste-te.”, "Tenho chefe."

$\rightarrow$ Entrevistadora: Hum, hum. Podia-me agora dizer, como é que foi, uma vez que já lá está há vinte e cinco anos, como é que foi a evolução da relação entre os trabalhadores e a entidade patronal? Por exemplo, eh a fábrica sempre foi um espaço de consensos, de conflitos? Uma vez que a FILOBRANCA passou por diferentes fases.

(3) ID: Entrevista RdA 1 MIC;

Tipo: Inquiridos

Data: 28/9/2010;

Local: Riba de Ave

(Zona de São Roque)

Entrevistadora do sexo feminino; e1: entrevistado do sexo masculino (marido); e2:entrevistada do sexo feminino (mulher)

$\rightarrow$ Entrevistadora: Portanto, partindo do que inicialmente agora estávamos aqui a falar e eh uma vez que esta era uma zona fortemente marcada pela têxtil eh podiam, se calhar, os dois até participar aqui na entrevista. Eh portanto vocês começaram na têxtil. No seu caso, sei que começou na Sampaio Ferreira, não é...

Entrevistado: Exatamente.

Entrevistada: Fomos os dois.

Estas pré-sequências de justificação "uma vez que já lá está há vinte e cinco anos" (exemplo 2) e "uma vez que esta era uma zona fortemente marcada pela têxtil" (exemplo 3) têm um carácter meta-discursivo, preparando a pergunta que incide sobre um tópico mais problemático (a relação entre o empregador e trabalhador, a relação entre o trabalhador e a indústria têxtil do Vale do Ave), redirecionando sequencialmente o 
modo como o assunto irá ser seguido, permitindo não apenas a organização temática dos tópicos da entrevista, mas também redirecionando o rumo discursivo das asserções realizadas pelos entrevistados, estando integradas numa estratégia de alinhamento em relação ao modo como os tópicos são abordados.

Verificamos a ocorrência de intensificadores nestas sequências de justificação como o advérbio de modo "fortemente" em "uma zona fortemente marcada pelo têxtil" (exemplo 3) e o uso do advérbio temporal "já" no adverbial temporal "já lá está há vinte e cinco anos" que permite intensificar a noção de que o entrevistado tem muita experiência de trabalho na fábrica até ao momento da enunciação em que é feita a entrevista.

Os autores da Análise Conversacional, como Pomerantz (1986 apud Meyers; Lampropoulou, 2012: 1215) referem que o uso destes intensificadores, que Edwards (2000: 347) chama de Extreme Case Formulations, ocorrem quando os participantes tomam consciência dos desafios que estão a dizer, regularmente, relacionados com a análise das condições de vida difíceis.

Os entrevistadores, com estas sequências, resumem o que foi dito e, simultaneamente, preparam o que vai ser dito, contribuindo para a coerência pragmática e funcional do discurso (Fonseca, 1992: 298) e demonstrando a colaboração que se estabelece entre entrevistador e entrevistado com o estabelecimento de um consenso que contribui para a consolidação da relação interlocutiva, como pode ser demonstrando pelo ato de acordo no exemplo 3 ("Exatamente").

\section{Ações dos entrevistados: as respostas dos entrevistados seguidas de sequências de justificação}

No corpus de entrevistas de investigação com uma natureza testemunhal - acentuada pela temática do desemprego, o fecho da fábrica, as representações da Escola e a análise das condições de vida da casa -, a justificação, realizada pelo entrevistado após o seu ato de resposta, constitui, regularmente, uma estratégia de mitigação dos valores ilocutórios mais ameaçadores para a sua própria face, uma vez que os entrevistados realizam atos de resposta com conteúdos proposicionais desvalorizadores do referente.

Nestes casos, as justificações são realizadas numa relação argumentativa em que a segunda parte do par " $p$ porque q" constitui um argumento que permite compreender o argumento expresso na primeira asserção. Assim, ao fazerem parte do conjunto dos mitigadores que reduzem as "obrigações epistémicas do locutor" (Caffi, 2000: 96), isto é, coocorrendo com asserções avaliativas com valor axiológico negativo, as justificações constituem mitigadores do valor de verdade expresso no conteúdo proposicional destas asserções.

Com efeito, segundo Fraser (2010), "hedging" is " a rhetorical strategy that attenuates either the full semantic of a particular expression (...) or the full force of a speech act (...)" (Fraser, 2010: 15).

Consideremos assim as sequências de justificação que ocorrem depois da pergunta do entrevistador e na vez de elocução de resposta do entrevistado:

(4) (E1 e E2: entrevistadoras do sexo feminino; e: entrevistada; 7 de junho de 2010; Residência)

Entrevistadora: E só um bocadinho antes disso, brincadeiras, que coisas...havia?

$\rightarrow$ Entrevistada: Não tinha brincadeiras, porque eu tinha que tomar conta dos meus irmãos. Eu não, os meus irmãos sim, mas eu não. Não porque tinha de tomar conta deles, que fui eu que tomei conta deles, não é? A minha mãe teve dezanove, de dezanove morreram doze, ficaram sete, não é?

$\mathrm{Na}$ justificação apresentada em (4), o segundo argumento "porque eu tinha que tomar conta dos meus irmãos" suporta a primeira asserção de resposta "Não tinha brincadeiras": a justificação mitiga o que é dito anteriormente no conteúdo proposicional da asserção anterior, criando uma distanciação do entrevistado em relação ao que é dito.

De acordo com Lopes (2009), a relação que a sequência de justificação estabelece com a asserção anterior é uma relação pragmática, requerendo, simultaneamente, uma sequência de atos de discurso e um processo inferencial. Assim, a justificação ocorre, prototipicamente, em contextos argumentativos (Idem: 241).

A argumentação é explicitada na relação "p porque q" e o locutor implicita a relação que se estabelece entre os dois argumentos, verificando que q constitui a justificação de $\mathrm{p}$.

A relação de Justificação é marcada, muitas vezes, pelo conectivo polifuncional "porque" (Idem: 245) dado marcar também a relação de Causa que é distinta da de justificação: a primeira relação envolve apenas um ato ilocutório enquanto que a Justificação envolve dois atos ilocutórios (Idem: 246).

\footnotetext{
4.1. O papel interacional dos marcadores de vagueza ("fuzziness markers"): as justificações seguidas de pergunta-tag e os diminutivos como suavizadores
} 
Segundo Laver (1981), a sequência de justificação é um comentário de mitigação ao serviço de uma estratégia de evitação de ameaça potencial realizada por um ato de discurso produzido anteriormente: de acordo com o autor, a uma saudação de despedida com votos futuros segue-se, regularmente, uma justificação desta saudação.

No corpus de entrevistas em análise, a justificação ocorre, regulamente, após o ato de pergunta-resposta, sendo esta última, regularmente, dadas as condições difíceis de vida em análise, uma asserção avaliativa com valor axiológico negativo.

Verificamos também, neste contexto de entrevista, que a uma sequência de justificação se segue, regularmente, um pergunta-tag.

A pergunta-tag, nestes contextos interacionais, permite demonstrar que o conhecimento é partilhado pelo entrevistador (Myers and Lampropoulou (2012): 1211; 1214).

Para além desta demonstração da colaboração dos interlocutores na construção conjunta das ações discursivas, a pergunta-tag que ocorre na sequência de justificação constitui também um mitigador do que é dito no conteúdo proposicional.

Observemos os seguintes exemplos:

(5) (E1 e E2: entrevistadoras do sexo feminino; e: entrevistada; 7 de junho de 2010; Residência)

Entrevistadora 1: Gostávamos que falasse da sua vida, da sua história, das pessoas com quem vive.

Entrevistadora 2: Portanto, eu gostava que começasse a falar de como é que era a sua vida, como é que foi a sua infância?

$\rightarrow$ Entrevistada: A minha infância foi muito difícil. Hum, tinha um ano e meio deu-me a paralisia infantil, deu-me a paralisia infantil, estive internada na Foz cinco anos e estive um ano e tal no hospital de Riba de Ave. Foi até aos seis, sete anos. Depois a escola, com muitas dificuldades, nasci de uma familia pobre, não é?

(6) (E1 e E2: entrevistadoras do sexo feminino; e: entrevistada; 7 de junho de 2010; Residência)

Entrevistadora: E como é que era a questão da alimentação?

$\rightarrow$ Entrevistada: Era como estava a dizer, quando eu fui para Delães passei muita necessidade, não é? [sequência de justificação] Porque foi na altura que a minha mãe não tinha...

As sequências de justificação "[porque] nasci de uma família pobre” (exemplo 5) e "Porque foi na altura que a minha mãe não tinha..." (exemplo 6) permitem justificar a asserção de resposta de que a infância da entrevistada foi difícil (exemplo 5) e a situação de fome vivida pela entrevistada. A pergunta-tag que ocorre na asserção do exemplo (5) "nasci de uma família pobre, não é?" e na asserção do exemplo (6) "passei muita necessidade, não é?" constitui "um modo suave de realizar o ato de asserção" (Fraser 1980: 349), isto é, estamos perante uma estratégia de mitigação do que é dito no conteúdo proposicional da asserção.

O exemplo (6) permite confirmar o teste sintático apresentado por Lopes (2009: 248) que salienta a possibilidade de a Justificação poder ocorrer depois de uma pergunta-tag: "passei muita necessidade, nãa é? Porque foi na altura que a minha mãe não tinha..."

A sequência de justificação e a pergunta-tag que coocorrem, simultaneamente, com a resposta a uma pergunta representam uma estratégia de mitigação, funcionando como mitigadores ou suavizadores ("softeners", segundo Caffi, 2000; cf. também Sifianou, 1992) do que é dito no conteúdo proposicional das asserções que, argumentativamente, estão relacionadas. Estamos perante aquilo a que os autores chamam de "fuzziness markers" or "hedging" (Fraser, 2010), isto é, uma "estratégia retórica" ao serviço da eficiência argumentativa (Fraser, 2010: 14), pois permite aos interactantes a aproximação ao valor de verdade do que é dito, "reduzindo as obrigações epistémicas" dos entrevistados (Caffi, 2000).

Ocorrem, depois das respostas a perguntas, sequências de justificação com o uso de lexemas no diminutivo, constituindo estes últimos suavizadores ou atenuadores (Sifianou, 1992) do que é dito:

(7) (E1 e E2: entrevistadoras do sexo feminino; e: entrevistada; 7 de junho de 2010; Residência)

Entrevistadora 1: E como é que era a sua casa?

Entrevistada: A minha casa era muito velhinha.

Entrevistadora 1: eh pequenina ou grande?

$\rightarrow$ Entrevistada: Era pequena. Um quarto tinha que dar para rapazes e raparigas e depois nos últimos anos, a minha mãe teve que ir buscar o pai dela, porque estava abandonado, e o quarto da minha mãe foi para o meu avô, e depois a minha mãe acabou por juntar-se a nós. Cheguei a dormir com a minha mãe e com o meu pai, cheguei a dormir com o meu pai. O meu pai naquela altura usava-se ceroulas, e ele dizia-me "Podes dormir à vontade que eu não te toco." Era criancinha. 
A asserção avaliativa acerca da casa, realizada no grau superlativo analítico, permite à entrevistadora produzir uma sequência de pergunta alternativa (Rodrigues, 1998: 48) através de uma estrutura disjuntiva "eh pequenina ou grande?" e que tem a função de pedir uma decisão acerca do valor de verdade da pergunta (Idem). Esta pergunta possibilita a resposta "Era pequena", seguida da sequência de justificação "um quarto tinha que dar para rapazes e raparigas...". A asserção "Era criancinha” funciona como uma justificação das asserções e, neste caso, a justificação com o lexema no diminutivo atenua o valor epistémico do que é dito no conteúdo proposicional da asserção e permite relacionar, argumentativamente, as asserções realizadas na narrativa de experiência de vida.

\section{Identidades na fala}

Relacionada com a variedade de temas abordados está a construção, na estrutura sequencial do discurso dos interactantes, do que Harvey Sacks (1995), no âmbito da Análise Conversacional, chamou de identidades discursivas relevantes para a ação, associadas ao dispositivo conversacional, como por exemplo, entrevistador e entrevistado, que permitem a realização de tarefas como perguntar e responder e outras ações relevantes para a sequencialidade discursiva, como as identidades situadas (Zimmerman, 1998), orientadas pelas posições institucionais que os interactantes assumem.

Verifica-se, assim, na linha de Harvey Sacks, dos autores da Análise Conversacional em geral e da tradição etnometodológica de Harold Garfinkel (1967), que a compreensão dos interactantes é feita localmente, isto é, torna-se fundamental analisar as práticas discursivas quotidianas (Antaki; Widdicombe, 1998: 1-2) e o modo como são verbalizadas as identidades discursivas no decorrer da ação conversacional.

Observemos o seguinte exemplo:

(8) (E1 e E2: entrevistadoras do sexo feminino; e: entrevistada; 7 de junho de 2010; Residência)

Entrevistadora: E castigos...

$\rightarrow$ Entrevistada: Não, nunca tive, não, não. Eu sempre me portei no meu lugar, nunca tive castigos. Não, não, como acabei de dizer, eles eram todos meus amigos. Eu era aleijada, não é?

Nesta situação em apreço, a entrevistada constrói toda a narrativa de experiência de vida em torno da deficiência que tem numa perna e esta identidade situada é relevante para a sequencialidade das ações narradas a propósito da sua vivência da fábrica. A pergunta-tag “não é??", no final da asserção "Eu era aleijada”, é uma estratégia de mitigação do que é dito no conteúdo proposicional da asserção.

Consideremos ainda o seguinte exemplo:

(9) (E1 e E2: entrevistadoras do sexo feminino; e: entrevistada; 7 de junho de 2010; Residência)

Entrevistadora: Não havia nenhum regulamento?

Entrevistada: Não, a mim não. Lá o Senhor Doutor que era o patrão, era uma pessoa muito bem dada connosco, comigo e com a minha mãe, ou era por ser muito amigo da minha mãe ou isso, já não ... que a minha mãe foi sempre muito bem querida lá naquela fábrica. Isso também ajudou muito, não é? Eu quando me sentia muito cansada, que sou aleijada, não é?

Entrevistadora: Se para uma pessoa qualquer já era difícil...

A justificação em (9) "que [porque] sou aleijada, não é” constitui um dispositivo de categorização de pertença a uma comunidade ("membership categorization device", no dizer de Harvey Sacks, 1995) que permite construir identidades discursivas relevantes para a interação em termos de sequencialidade e/ou construção das vezes de elocução (Fitzgerald e Housley, 2002: 580-581). É através desta abordagem do modelo de "membership categorization analysis" (MCA) e da Análise Conversacional (AC) que podemos demonstrar como as categorias de pertença a uma comunidade são construídas e desenvolvidas no rumo discursivo (Idem). Este dispositivo permite desenvolver experiências partilhadas e convocar lugares comuns para lidar com dilemas colocados pelas perguntas que ocorrem na interação em situação de entrevista, constituindo uma forma de o entrevistado lidar com um problema retórico (Myers; Lampropoulou, 2012: 1209).

\section{Conteúdo proposicional das justificações}


Nas entrevistas em análise, a uma sequência iniciativa de pergunta segue-se a sequência reativa de resposta e esta última é seguida de uma justificação. Verificamos, assim, que o argumento p apresentado na asserção que funciona como ato de resposta constitui um ato dominante apoiado por um ato subordinado de justificação ${ }^{1}$.

A justificação tem um "efeito retroactivo" (Fonseca, J., 1996: 87) no discurso, sendo um ato de natureza sequencial (Idem): a justificação acaba por especificar as razões que explicam a situação que é relatada pelo entrevistado e constitui também uma forma de o entrevistado minimizar a ameaça da sua própria face positiva que é visada pela primeira asserção de resposta e tem como tópico as suas condições de vida.

Em síntese, é possível estabelecer uma tipologia de justificações apresentadas pelos entrevistados inquiridos nas entrevistas em análise. De acordo com o corpus aqui utilizado, encontramos o seguinte:

\section{JUSTIFICAÇÃO}

\begin{aligned} \hline Conteúdo proposicional: & $<$ E não tem condições para brincar porque tem de tomar \\ & conta dos irmãos $> \\ & <$ a infância de E foi difícil porque nasceu numa família \\ & pobre $> \\ & <$ E passou fome porque a mãe não tinha comida para lhe \\ & dar $> \\ & <$ a casa de E era pequena porque um quarto dava para \\ & raparigas e rapazes $> \\ & <$ E nunca foi castigado na fábrica porque era aleijada $> \\ & <$ E podia abrandar o ritmo de trabalho na fábrica porque \\ & era aleijada $>\end{aligned}$

Legenda: $\mathrm{E}=$ entrevistado ou entrevistada

\section{Conclusão}

No corpus de entrevistas em análise, as posições institucionais dos entrevistados perante a Escola, o Trabalho e a Casa onde habitam criam a construção de uma imagem institucional dos entrevistados caracterizada pela pobreza, a fome, o insucesso na Escola, a desvantagem social e o conformismo.

Os entrevistadores preparam o ato de pergunta com pré-sequências de justificação, realizam um dispositivo que faz parte de uma retórica do consenso com a realização de intensificadores ("Extreme Case Formulations") que possibilitam o acordo entre os interactantes. Estas pré-sequências preparam o ato de pergunta salvaguardando as faces dos entrevistados. Com efeito, este dispositivo retórico insere-se no seio de estratégias discursivas de alinhamento e são, assim, uma forma de o entrevistador estabelecer não só relações de coerência na narrativa de experiência de vida que é partilhada na situação de entrevista, mas também de permitir a salvaguarda das faces.

Por seu lado, os entrevistados, nestas entrevistas de investigação, com temas que dizem respeito à relação com o trabalho (o trabalho na fábrica), com a Escola, a casa e a deficiência, realizam asserções com valor axiológico negativo que diz respeito às dificuldades que têm de enfrentar e, por isso, desenvolvem dispositivos com o objetivo de, retoricamente, evitar ameaçar, por mais tempo, a sua própria face positiva: os entrevistados produzem asserções seguidas de justificações. Estas coocorrem com perguntas-tag e, regularmente, apresentam lexemas no diminutivo para mitigar o valor epistémico de verdade presente no conteúdo proposicional destas asserções, permitindo a distanciação em relação ao que é dito. Nestes enunciados de cariz testemunhal, no seio da sequência de justificação, os entrevistados realizam também identidades situadas relevantes para a ação conjunta na situação de entrevista que permitem situar o seu discurso ancorando-o numa posição interacional específica que lhes permite continuar a desenvolver a narrativa sobre as condições de vida difíceis experienciadas.

\section{Referências}

Almeida, Carla Aurélia de (1998) O acto ilocutório de oferta em português. In J. Fonseca (org.) A organização e o funcionamento dos discursos. Estudos sobre o Português, Tomo III. Porto: Porto Editora, pp. 157-221.

\footnotetext{
${ }^{1}$ Sobre a relação entre o ato dominante de recusa e o ato subordinado de justificação na sequência discursiva de oferta-recusa-justificação, ver Almeida, 1998: 187.
} 
(2012) 'Que eu já nasci em Riba de Ave. [...] Sempre me conheci aqui em Riba de Ave (risos)': a coconstrução do sentido em narrativas de experiência de vida no Vale do Ave. In. Virgílio Borges Pereira, (org.) Ao cair do pano. Sobre a formação do quotidiano num contexto (des)industrializado do Vale do Ave. Porto: Afrontamento, pp. 417-445.

Antaki, Charles; Widdicombe, Sue (eds.) (1998) Identities in talk. London: Sage.

Bacelar do Nascimento, Maria Fernanda et al. (1987) Português fundamental, métodos e documentos, Tomo 1 inquérito de frequência. Lisboa: INIC, CLUL.

Brown, Penelope; Levinson, Stephen (1978) Universals in language Use: Politeness phenomena. In. Esther Goody (ed.), Questions and politeness: strategies in social interaction. Cambridge: Cambridge University Press, pp. 56-289.

(1987) Politeness. Some universals in language use. Cambridge: CUP.

Caffi, Claudia (2000) Aspects du calibrage des distances émotives entre rhétorique et psychologie. In. Christian Plantin et al. Les émotions dans les interactions. Lyon : Presses Universitaires de Lyon, pp. 89-104.

Drew, Paul; Raymond, Geoffrey; Weinberg, Darin (eds.) (2006) Talk and interaction in social research methods. London: Sage.

Edwards, Derek (2000) Extreme case formulations: softeners, investment and doing nonliteral. Research on language and social interaction, 33, 4, pp. 347-373.

Fitzgerald, Richard; Housley, William (2002) Identity, categorization and sequential organization: the sequential and categorical flow of identity in a radio phone-in. Discourse and Society, vol. 13, 5, pp. 579-602.

Fonseca, Joaquim (1992) Linguística e texto / discurso - teoria, descrição, aplicação. Lisboa: Ministério da Educação / Instituto de Cultura e Língua Portuguesa.

(1996) O discurso de Corte na Aldeia de Rodrigues Lobo - o Diálogo I. Revista da Faculdade de Letras do Porto - Linguas e Literaturas. Porto, Vol. XIII, pp. 87-145.

Franck, Dorothea (1981) Seven sins of pragmatics - thesis about speech act theory, conversational analysis, linguistics and rhetoric. In. Herman Parret; Marina Sbisà e Jef Verschueren (eds.) Possibilities and limitations of pragmatics. Amesterdam: John Benjamins, pp. 225-236.

Fraser, Bruce (1980) Conversational mitigation. Journal of Pragmatics 4 (4), pp. 341-350.

Fraser, Bruce (2010) Pragmatic competence: the case of hedging. In Kaltenböck, Gunther; Mihatsch, Wiltrud; Schneider, Stefan (ed.) New Approaches to Hedging, Bingley, Emerald Group Publishing, pp. 15-34.

Goffman, Erving (1974) Les rites d'interaction. Paris: Les Éditions de Minuit.

(1981) Forms of talk. Philadelphia: University of Pennsylvannia Press.

Goodwin, Charles; Goodwin, Marjorie Harness (1987) Notes on the Interactive Organization of Assessments. IPRA Papers in Pragmatics l, No.1, pp. 1-54.

Gumperz, John (1982) Discourse strategies. Cambridge: Cambridge University Press.

Houtkoop-Steenstra, Hanneke (2000) Interaction and the standardized survey interview. The living questionnaire, Cambridge: Cambridge University Press.

Kerbrat-Orecchioni, Catherine (2010) The case for an eclectic approach to discourse-in-interaction. In. Jürgen Streeck (ed.) New adventures in language and interaction. Amsterdam/ Philadelphia: John Benjamins Publishing Company, pp. 71-97.

Laver, John (1981) Linguistic routines and politeness in greeting and parting. In. Florian Coulmas (ed.) Conversational routine. Explorations in standardized communication situations and prepatterned speech. The Hague: Mouton, pp. 289-304.

Lopes, Ana Cristina Macário (2009) Justification: a coherence relation. Pragmatics 19: 2, pp. 241-252.

Myers, Greg; Lampropoulou, Sofia (2012) Impersonal you and stance-taking in social research interviews. Journal of Pragmatics 44, pp. 1206-1218.

Pedro, Emília Ribeiro (1993) À volta dos diminutivos. Uma análise contrastiva entre o português e o inglês. Actas do VIII encontro da Associação Portuguesa de Linguística. Lisboa: Colibri, pp. 402-417.

Pereira, Virgílio Borges (org.) (2012) Ao cair do pano. Sobre a formação do quotidiano num contexto (des)industrializado do Vale do Ave. Porto: Afrontamento.

Rodrigues, Conceição Carapinha (1998) A sequência discursiva pergunta-resposta. In. Joaquim Fonseca (org.) $A$ organização e o funcionamento dos discursos. Estudos sobre o português. Tomo II. Porto: Porto Editora, pp. 11-220.

Sacks, Harvey (1995) Lectures on conversation, vol. I, II. Oxford/ Cambridge: Blackwell.

Schegloff, Emanuel (1988) Presequences and indirection. Applying speech act theory to ordinary conversation. Journal of pragmatics, 12, 1, pp. 55-62.

Searle, John R. (1982) Sens et expression. Paris: Les Éditions de Minuit.

Sifianou, Maria (1992) The use of diminutives in expressing politeness: Modern Greek Versus English. Journal of Pragmatics 17 (2), pp. 155-173. 
Tannen, Deborah (2001) The relativity of linguistic strategies: rethinking power and solidarity in gender and dominance. In. Margaret Wetherell et al., Discourse theory and practice. A reader, London, Sage pp. 150166.

Verschueren, Jef (1980) À la recherche d'une pragmatique unifiée. Communications, 32, pp. 274-284.

Verschueren, Jef (1991) The pragmatic perspective. In. Verschueren, Jef; Bertuccelli-Papi, Marcella (eds.) The pragmatic perspective selected papers from the 1985 international pragmatics conference. Amsterdam/ Philadelphia: John Benjamins Publishing Company, pp. 1-8.

Verschueren, Jef (1999) Understanding Pragmatics. London: Edward Arnold.

Wooffitt, Robin; Widdicombe, Sue (2006) Interaction in interviews. In Drew, Paul; Raymond, Geoffrey;

Weinberg, Darin (eds.) (2006) Talk and interaction in social research methods. London: Sage. 